\title{
Cellular and molecular basis of decision-making
}

\author{
Nilay Yapici $^{1}$, Manuel Zimmer ${ }^{2}$ \& Ana I Domingos ${ }^{3, *}$
}

\begin{abstract}
People think they are in control of their own decisions: what to eat or drink, whom to marry or pick a fight with, where to live, what to buy. Behavioural economists and neurophysiologists have long studied decision-making behaviours. However, these behaviours have only recently been studied through the light of molecular genetics. Here, we review recent research in mice, Drosophila melanogaster and Caenorhabditis elegans, that analyses the molecular and cellular mechanisms underlying decision-making. These studies interrogate decision-making about food, sexual behaviour, aggression or foraging strategies, and add molecular and cell biology understanding onto the consilience of brain and decision.
\end{abstract}

Keywords aggression; decision-making; nutrient sensing; obesity; sexual behaviour

DOI 10.15252/embr.201438993 | Received 30 April 2014 | Revised 19 August 2014 | Accepted 25 August 2014 | Published online 19 September 2014

EMBO Reports (2014) 15: 1023-1035

See the Glossary for abbreviations used in this article.

\section{Introduction}

Behavioural economists seek an understanding of the psychological mechanisms underlying decision-making, which could ultimately translate into models that predict market behaviour [1,2]. The idea that decisions are taken through a rational and logical thought process has been put into question by multiple behavioural economic experiments that analyse subjective evaluation during decision-making [3]. For instance, subjects can prefer a more painful stimulus to a less painful one, if the latter lasts longer [4]. In fact, an individual's judgment about the value of stimulus, object or action can change not only by changing wait time, but by changing context, trade-off between intensity and duration, between cost and benefit, or risk and certainty, to name a few factors [4-6]. This rich behavioural phenomenology has been a topic of study in the fields of neuroeconomy, neuromarketing and neurophysiology [7-12].

A market behaviour that has puzzled food industry analysts is that the market share of regular soda more than doubles that of diet soda. This trend persists since artificial sweeteners first appeared in the market $[13,14]$. The identification of mammalian sweet taste receptors (TRs) accelerated the identification of non-nutritivespecific TR agonists that mimic the sensory action of sugar in lingual taste buds. However, given the epidemiological trend of increasing obesity, and forceful decisions about restricting sugar consumption, the soda market behaviour indicates that there is an irrational element about how people chose what to consume. Why do people decide to prefer sugary drinks to diet drinks, even if the associated health costs are higher? The answer to this difficult question is multifaceted, and biology may play a predominant role. Recent studies in genetically tractable organisms such as mice and the fruit fly validate the notion that the drive to decide for sugar over non-nutritive sweeteners is controlled by specific populations of neurons. The same concept is illustrated by multiple examples of decisions about sexual mates. Genetically tractable model organisms can be used for probing the role of molecularly identified circuits, neurons and molecules during behavioural decision-making. Indeed, the biology of decision-making behaviours has been recently analysed under a molecular genetics perspective. Here, we review recent studies that use mice, Drosophila melanogaster or Caenorhabditis elegans, to investigate the molecular and cellular mechanisms underlying decision-making.

\section{Nutrient sensing: neurons that control decisions about food}

Studies in mice and fruit flies have identified neurobiological mechanisms explaining sweetener preference. When given the direct choice between a nutritive sweetener containing glucose, a nutritive sugar such as sucrose, and a non-nutritive sweetener such as sucralose, mice prefer the former [15]. This preference is a result of the post-ingestive rewarding effect of sucrose [15]. This effect of sucrose was first described by showing that non-nutritive liquids that are paired to glucose administration either in the intra-gastric tract or in plasma are greatly preferred over liquids that are not paired with nutrients. In addition, rodent studies have shown that sucrose but not sucralose can drive dopamine (DA) release in the midbrain, even in the absence of taste $[16,17]$. Sweet-blind Trpm5 knockout mice can still sense the nutrient value of sucrose, which biases decisionmaking behaviour [16]. These studies indicate that the nutrient value of sucrose is sensed and establishes a preference for nutritive sugars. The combination of sweet taste and an increase of dopamine

\footnotetext{
1 Laboratory of Neurogenetics and Behavior, The Rockefeller University, New York, NY, USA

2 Research Institute of Molecular Pathology (IMP), Vienna Biocenter (VBC), Vienna, Austria

3 Obesity Laboratory, Gulbenkian Science Institute, Rua Da Quinta Grande, Oeiras, Portugal

*Corresponding author. Tel: +351 214464517; E-mail: dominan@igc.gulbenkian.pt
} 


\begin{tabular}{|c|c|}
\hline \multicolumn{2}{|l|}{ Glossary } \\
\hline 5-HT & serotonin \\
\hline 7,11-HD & 7,11-heptacosadiene \\
\hline $7-T$ & 7-tricosene \\
\hline ARS & area-restricted search \\
\hline asc & ascaroside \\
\hline ATF4 & activating transcription factor 4 \\
\hline cGMP & cyclic guanosine monophosphate \\
\hline ChR2 & channelrhodopsin \\
\hline cVA & cis-vaccenyl acetate \\
\hline DA1 & dorsal anterior 1 \\
\hline DA-DL1 & dopaminergic dorso lateral 1 cluster \\
\hline DA & Dopamine \\
\hline DA-PAM & protocerebral anterior medial cluster \\
\hline DC1 & dorsal cluster 1 \\
\hline$D E G / E N a C$ & degenerin/epithelial $\mathrm{Na}^{+}$channel \\
\hline DN1 & decending neuron 1 \\
\hline DopEcr & dopamine/ecdysteroid receptor \\
\hline$d s x$ & doublesex \\
\hline fru & fruitless \\
\hline GABA & gamma-aminobutyric acid \\
\hline GCN2 & general control non-derepressing-2 \\
\hline GPCR & $\mathrm{G}$ protein-coupled receptor \\
\hline $\mathrm{Gr}$ & gustatory receptor \\
\hline GRNs & gustatory (taste) receptor neurons \\
\hline INS-1 & insulin-like peptide-1 \\
\hline IR & ionotropic glutamate receptor \\
\hline LH & lateral hypothalamus \\
\hline MB & mushroom bodies \\
\hline MCH & melanin-concentrating hormone \\
\hline MUPs & mouse urinary proteins \\
\hline NLP-1 & neuropeptide-like protein-1 \\
\hline$n p r-1$ & neuropeptide receptor-1 \\
\hline Or67d & olfactory receptor $67 d$ \\
\hline OSN & olfactory sensory neurons \\
\hline P1 & fruitless (fru)/doublesex ( $d s x)$-coexpressing neuronal cluster \\
\hline P2b & descending interneuron \\
\hline PAA & phenylacetic acid \\
\hline PA & phenylacetaldehyde \\
\hline PDF & pigment dispersing factor \\
\hline PER & proboscis extension response \\
\hline pIP10 & descending interneuron \\
\hline PN & projection neurons \\
\hline ppk & pickpockets \\
\hline SEZ & subesophageal zone \\
\hline SLC5A11 & sodium/solute co-transporter-like protein \\
\hline TG & thoracic ganglia \\
\hline TGFbeta & transforming growth factor beta \\
\hline TH-Vum & tyrosine hydroxylase-ventral unpaired median \\
\hline Tk & tachykinin \\
\hline TOR & target of rapamycin \\
\hline TRPC2 & $\begin{array}{l}\text { transient receptor potential cation channel, subfamily } \mathrm{C} \\
\text { member } 2\end{array}$ \\
\hline Trpm5 & $\begin{array}{l}\text { transient receptor potential cation channel, subfamily } M \text {, } \\
\text { member } 5\end{array}$ \\
\hline TRs & taste receptors \\
\hline Va1v & ventral most compartment of ventroanterior 1 \\
\hline VI2a & anterior- and dorsal-most compartment of ventrolateral 2 \\
\hline VMH & ventromedial hypothalamus \\
\hline
\end{tabular}

accounts for the preference for natural sweeteners as compared to artificial ones [15]. The artificial sweetener sucralose is only preferred to sucrose if supplemented with a proxy for this post-ingestive reward, which was provided by optogenetic activation of DA neurons [15] (Fig 1A-E).
The post-ingestive rewarding effect plays an important role in driving decision-making behaviour during sweetener choice. The elements of the neural circuit that convey the post-ingestive rewarding effect of sucrose have been recently identified-melaninconcentrating hormone $(\mathrm{MCH})$-expressing neurons in the lateral hypothalamus (LH) influence decision-making behaviour during sweetener choice [18]. MCH neurons in the LH are glucose sensitive and have increased activity when extracellular glucose levels increase $[19,20]$. Glucose-activated $\mathrm{MCH}$ neurons and pancreatic $\beta$ cells share signal transduction components necessary for glucose sensing, which regulate the glucose excitability of $\mathrm{MCH}$ neurons [20]. In addition, $\mathrm{MCH}$ neurons send dense projections to reward centres in the striatum and midbrain, where dopaminergic neurons are located [18]. This strong anatomical connection between $\mathrm{MCH}$ neurons and reward nuclei, as well as the fact that $\mathrm{MCH}$ neurons sense glucose levels, placed these hypothalamic neurons in a good position for being mediators of the rewarding value of sucrose. Indeed, $\mathrm{MCH}$ neurons are necessary and sufficient for establishing a preference for sucrose over sucralose during decision-making behaviour [18] (Fig 1D and E). In vivo microdialysis in behaving mice shows that $\mathrm{MCH}$ neural activation increases dopamine release in the striatum and that the increase of dopamine in response to sucrose is lost after ablation of $\mathrm{MCH}$ neurons [18]. Specific ablation of $\mathrm{MCH}$ neurons can be achieved in mice using transgenic tools that allow tissue-specific expression of diphtheria toxin receptor exclusively in MCH neurons [21]. Animals with tissue-specific ablation of $\mathrm{MCH}$ neurons no longer prefer sucrose to sucralose and show reduced striatal DA release upon sucrose ingestion. Conversely, activation of $\mathrm{MCH}$ neurons during intake of the artificial sweetener sucralose increases striatal DA levels and inverts the normal sweetener preference [18]. The specific activation of these neurons during sucralose ingestion can be achieved in mice using channelrhodopsin, a light-activated cation channel that allows remote activation of genetically identified populations of neurons during behaviour $[18,22]$. However, optogenetic stimulation of $\mathrm{MCH}$ neurons alone is not sufficient to alter behaviour in the absence of taste [18], suggesting that these neurons are components of a reward-encoding network that integrates information from multiple sources, including the nutrients, lingual taste buds and, possibly, other sites of glucose sensing, such as the gut. Consistent with this possibility, viral tracing from lingual taste buds shows that $\mathrm{MCH}$ neurons are part of a circuit processing gustatory information [23]. This is also consistent with the requirement for both sweet taste and optogenetic activation of $\mathrm{MCH}$ neurons to drive reward. The nutrient-sensing role of $\mathrm{MCH}$ neurons contrasts with the role of DA neurons or serotonergic neurons, which upon optogenetic stimulation have been shown to be rewarding when paired to water [15,24] (Fig 1A-E).

A synergy between taste and the post-ingestive rewarding effect would explain why sucrose and other fructose/glucose disaccharides, which are more potent stimulators of sweet taste receptors than glucose alone, are generally preferred to glucose alone $[25,26]$. This synergy would also explain why optogenetic gain of function of $\mathrm{MCH}$ neurons leads to an inversion of preference, rather than an isopreference, which could perhaps have been achieved by decreasing the concentration of sucralose. Likewise, the loss of function of $\mathrm{MCH}$ neurons leads to isopreference, but this might be biased towards sucralose by increasing its concentration. Further studies will be necessary to elucidate the neural mechanisms by which $\mathrm{MCH}$ 
neurons regulate striatal DA release during sweetener intake (Sidebar A). The delineation of this decision-making neural circuit may also provide a basis for understanding how metabolic state modulates the rewarding value of sugar [15]. The adipostat hormone leptin regulates the reward value of sucrose, but this is unlikely to be a result of a direct effect on $\mathrm{MCH}$ neurons, as they do not appear to express the leptin receptor [27] (Sidebar A). However, leptin has been recently reported to act presynaptically to suppress excitatory synaptic input onto midbrain DA neurons [28] (Sidebar A).

Nutrient sensing that guides decision-making about sweetener ingestion has also been studied in Drosophila and found to be regulated at the central nervous system level. Brain nutrient sensing may therefore represent an evolutionary adaptation to avoid fasting, by expediting decisions about which foods to consume. We speculate that nutrient sensing in the brain could be ancient in the evolutionary scale, whereas peripheral detection would be a relatively modern adaptation.

Flies regulate food intake to balance metabolic homeostasis and maintain a stable body weight. Feeding decisions are controlled by at least three factors: taste sensory cues, metabolic status and nutrient sensing (Fig 1F). Similar to humans and mice, flies like sugars and avoid bitter compounds [29]. After finding food, flies determine the palatability of the food source and decide whether to sample or not. Food palatability is sensed through gustatory (taste) receptor neurons (GRNs) that are distributed across the proboscis (mouth) and legs [30,31]. GRNs express a set of gustatory receptor (Gr) genes, which belong to a highly divergent family of seven transmembrane G protein-coupled receptors [32-34]. Grs that are required for sweet and bitter compound sensation have been identified by behavioural and electrophysiological analysis [35-39]. In addition to Grs, GRNs have been recently shown to express ionotropic glutamate receptor (IR) genes [40,41] and the degenerin/epithelial $\mathrm{Na}^{+}$channel (DEG/ $\mathrm{ENaC}$-encoding genes, pickpockets (ppk) $[42,43]$. The fly taste system also detects water and other macronutrients - such as amino acids and fatty acids [35,43-45] (Sidebar A).

The metabolic status of the fly regulates its responsiveness to taste stimuli. Flies that have been food-deprived are more likely to respond to sugar stimulus, compared to flies that have recently fed [46]. DA signalling regulates sensitivity to sugar stimulus by enhancing sugar-evoked responses of GRNs. This effect of DA is abolished after Dopamine/Ecdysteroid receptor (DopEcr) knock-down in sugarsensitive GRNs [47]. However, the source of DA release that primes GRNs to sugar is unknown. A group of DA neurons have been shown to regulate the sucrose-induced proboscis extension response (PER) [48]. One of these neurons, TH-VUM (Fig 1G), is located in the ventromedial region of the fly brain with extensive branching in the primary taste centre, the subesophageal zone (SEZ). The TH-VUM neuron is not directly involved in taste perception and may decrease the threshold for sugar stimulation when flies are food-deprived, therefore regulating action selection mechanisms for PER [48].

As mice, flies choose food based on nutritional value, not only taste sensory input. For example, taste-deficient flies prefer nutritive sweeteners to non-nutritive sweeteners after food deprivation $[49,50]$. This preference is independent of taste perception and is based on post-ingestive content (Fig 1F). A sodium/solute co-transporter-like protein (SLC5A11 or cupcake) was identified in a genetic screen for flies that fail to perform the correct nutritional preference [51]. cupcake is structurally related to mammalian sodium/glucose co-transporters that regulate sugar absorption in the digestive tract. Unlike the mammalian orthologs, cupcake is expressed in 10-13 pairs of central brain neurons located in the ellipsoid body (Fig 1G). cupcake mutant flies or flies with inactive cupcake neurons fail to discriminate nutritive sugar D-glucose over non-nutritive sugar L-glucose [51]. How cupcake neurons regulate preference for nutritive sweeteners is not clear, and two alternative mechanisms have been proposed. Cupcake-expressing neurons may be nutrient sensors for nutritive sugars that stimulate their consumption upon prandial rise in the haemolymph nutrient levels. Alternatively, cupcake neurons might monitor the internal metabolic status of flies and change sugar preference towards nutritive sugars upon fasting. Either of these hypotheses requires validation. One critical experiment would be to measure the activity of cupcake neurons in response to nutritive and non-nutritive sweeteners, in fed versus food-deprived flies. In addition to cupcake neurons, another population of neurons expressing Gr43a has been identified as a brain nutrient sensor for fructose [52]. These neurons are located in the lateral protocerebrum (Fig 1G) and can detect the rise in circulating fructose as a post-ingestive signal for sugar intake. Consistent with this, Gr43a mutants lose preference to sorbitol—a tasteless nutritive sugar alcohol-over water [52]. Activation of Gr43a neurons in food-deprived flies facilitates feeding, whereas in fed flies it causes feeding termination [52]. The opposing effects of Gr43a neurons in fed and food-deprived flies suggest that these neurons regulate food consumption depending on the internal state of the animal. The factors that regulate the state dependency remain unknown and may involve a crosstalk between Gr43a neurons and cupcake neurons. Anatomically, the processes of these neurons do not overlap, but they are in close proximity. It is possible that both of these neural populations communicate with the same, still unknown, central reinforcement system that regulates feeding decisions in flies (Sidebar A). In mice, the post-ingestive effect of sugar is regulated by DA neurons, as discussed above [15]. Given that nutritive sugar preference is conserved among flies and mice, it would not be surprising whether distinct populations of DA neurons are also involved in the reinforcement systems for nutritive sugar preference in flies. In agreement with this hypothesis, it has been shown that the rewarding effects of nutritive sugars are required for flies to form stable appetitive olfactory memories in an odour-taste association task $[53,54]$. A group of DA neurons in the DA-PAM is required for long-term appetitive memory formation, by encoding the reward value of sugar stimulus [55]. DA-PAM neurons receive inputs from octopaminergic (OA) neurons that are located in the SEZ and have output trajectories in the medial lobes of mushroom bodies (MB), the olfactory processing centre in the fly brain. It has been postulated that DA-PAM neurons integrate the gustatory reward and internal state information and convey reinforcement signals to MBs, where appetitive olfactory memories are likely to be formed and stored [55]. In addition to long-term appetitive memory formation, flies also show short-term appetitive olfactory memories that are reinforced by the action of $\mathrm{OA}$ signalling on a discrete subset of DA neurons that project to distinct MB lobes [56]. The neurophysiological properties and molecular mechanisms that encode short-term and long-term appetitive olfactory memories in the MBs are not clearly understood. The identification of smaller populations of DA neurons in MBs with distinct molecular identities and functions will provide valuable information to understanding short-term and 
A

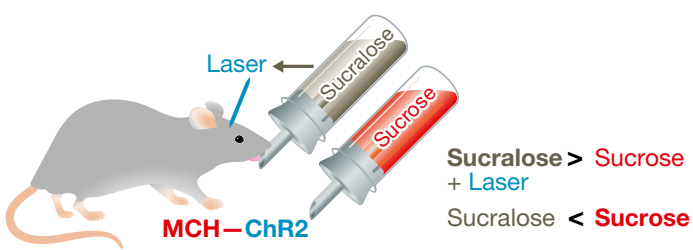

C

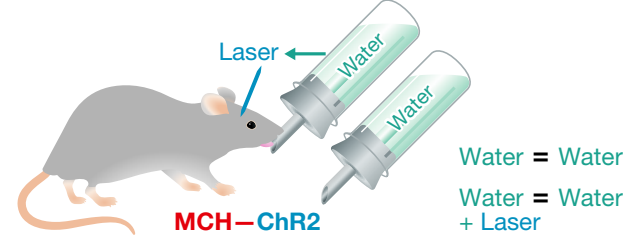

D

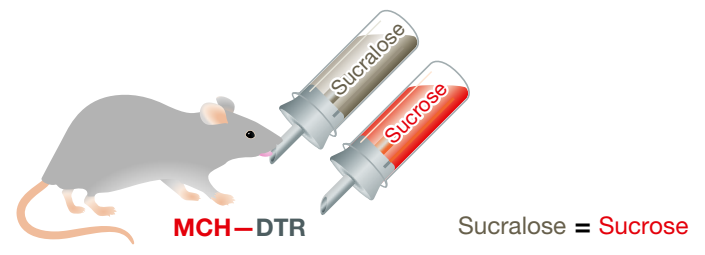

F

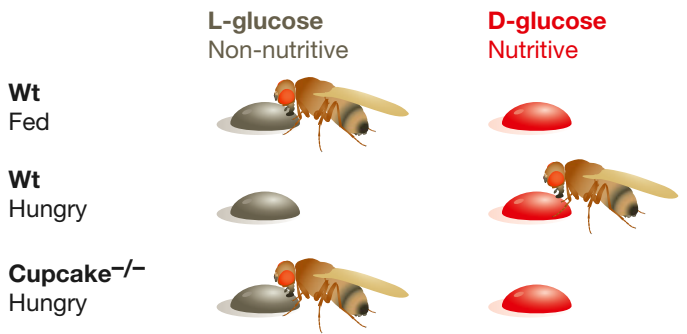

H

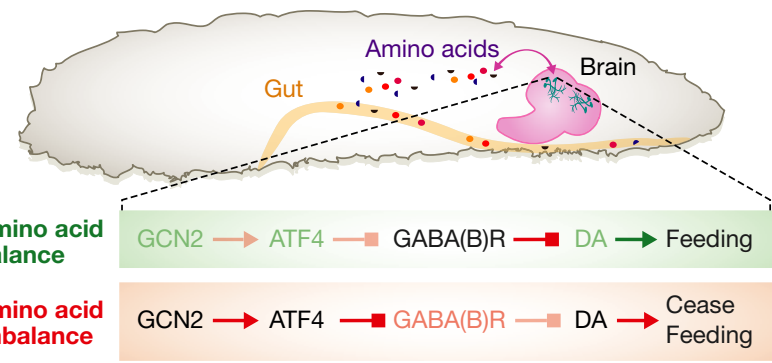

I

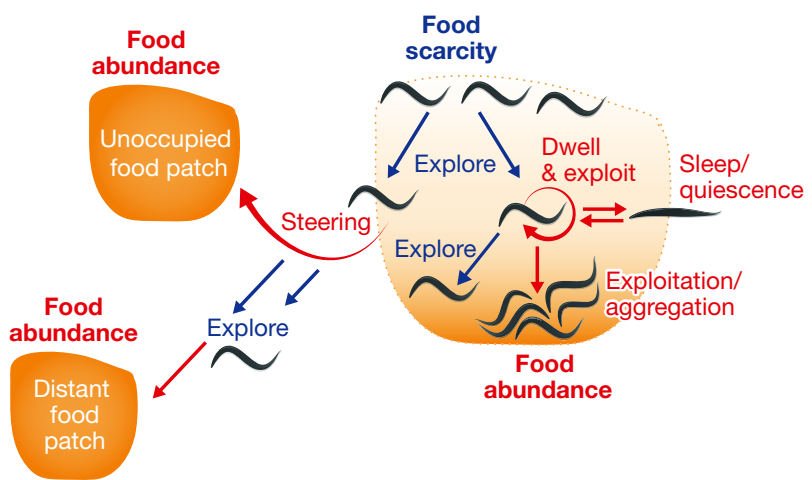

B

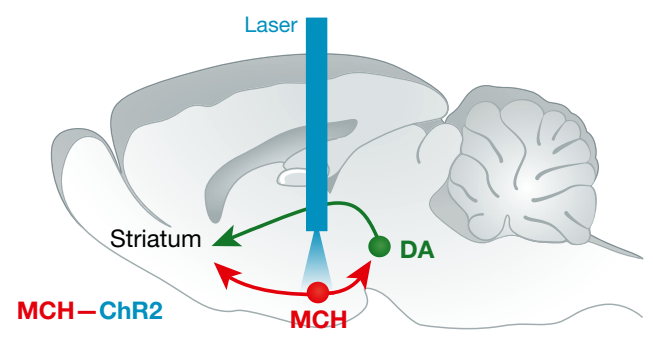

E

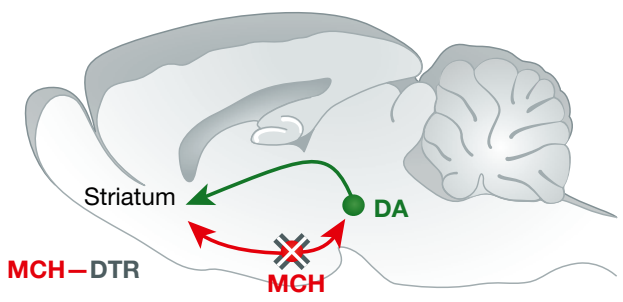

G

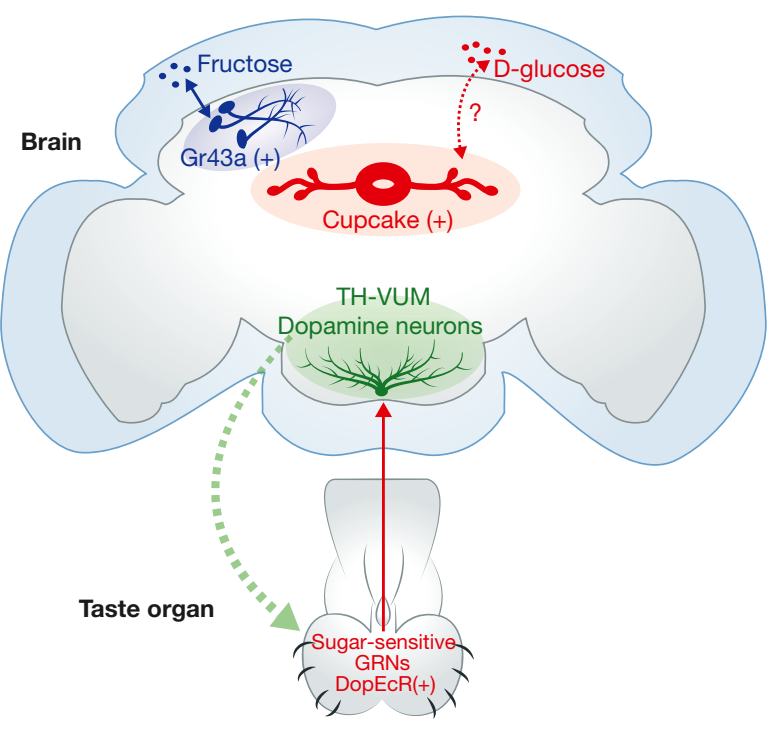

J

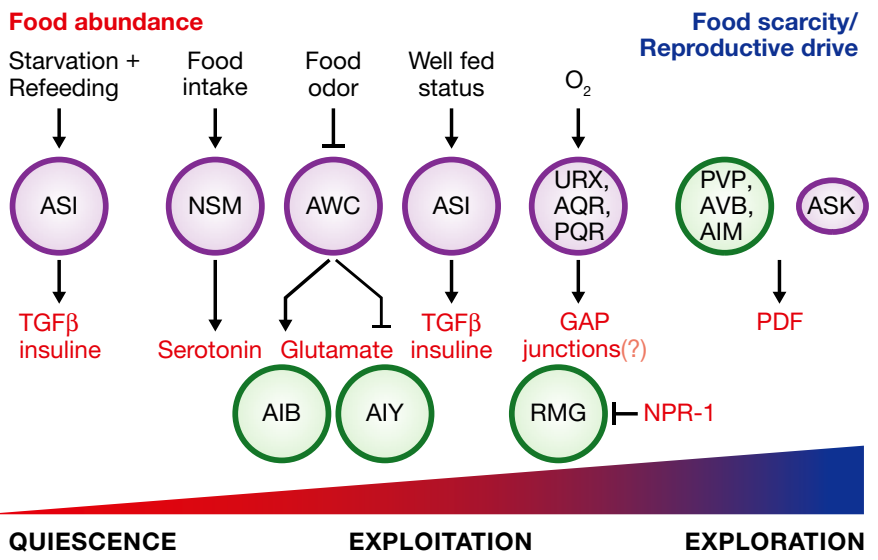


Figure 1. Nutrient sensing: controlling decisions about food.

(A, B) Optogenetic stimulation of glucose-sensitive $\mathrm{MCH}$ neurons during sucralose intake inverts preference for sucrose. (C) Optogenetic stimulation of $\mathrm{MCH}$ neurons during water intake does not create a bias towards laser side; thus, $\mathrm{MCH}$ neurons are not rewarding in the absence of taste. (D, E) Loss of glucose-sensitive MCH neurons decreases DA induction during sucrose intake and leads to isopreference between sucrose and sucralose. (F) Wild-type flies prefer nutritive sugar D-glucose to L-glucose when they are hungry. In cupcake mutants, the preference towards D-glucose is disrupted. (C) Representation of neurons that regulate proboscis extension response (PER) and nutritive sweetener preference. (H) Essential amino acid detection and food intake regulation in Drosophila larvae. During amino acid balance, the GNC2 pathway is inactive and GABA signalling inhibits DA release. When essential amino acid levels are perturbed, GCN2 is activated and inhibits GABA signalling, leading to DA release. (I) Food availability and nutritional status mediate foraging decisions in Caenorhabditis elegans. Low food abundance or low nutritional value promotes roaming across the food patch. In the presence of rich food supply, animals switch more often to local dwelling to exploit the food source. Severe starvation history causes prolonged sleep-like quiescence in this situation. If not successful in finding high-quality food locally, animals eventually take risk and decide to leave the patch to navigate directly to new food sources. Explorative deviations from their path serve to locate more distant eventually better food sources. ()) Neurons and transmitter pathways that act along an arousal axis, which ranges from sleep-like quiescence, via exploitation by dwelling and feeding, to explorative behaviours like roaming and patch leaving. Purple circles indicate sensory neurons; green circles indicate interneurons. See Glossary for definitions.

long-term appetitive olfactory memory formation and how nutrient rewards affect these processes. Thus, the fly system also provides an attractive model to characterize how food decisions are influenced by learning and memory mechanisms.

Sugars are the main food source for flies. However, their preference for sugars is altered when they are deprived of other nutrients such as amino acids (Sidebar A). A group of genes that regulate amino acid preference have been identified. These include the regulators of TOR pathway, such as tuberous sclerosis complex (TSC1\&2) and S6-kinase [57,58]. Although the molecular identities of these pathways are known, the underlying neural circuitry is yet to be found. A small population of DA neurons in the larval brain has recently been characterized as a nutrient sensor for essential amino acids [59]. Larvae refuse food depleted of certain essential amino acids, a response that is regulated by GCN2 kinase-dependent GABA signalling in DA neurons (Fig $1 \mathrm{H}$ ). Ex vivo calcium imaging of a small population of DA neurons (DA-DL1) indicates that they respond to the decrease in essential amino acid concentration in solution. This response is dependent on GCN2 or ATF4, a downstream molecule in GCN2 signalling [59]. How GCN2 signalling mediates the sensing of rapid fluctuations in amino acid concentrations and affects DA-DL1 neural activity remains unknown. DA-DL1 neurons are also present in the adult fly brain. Calcium imaging and behavioural experiments will show whether these neurons maintain their amino acid sensing ability and regulate amino acid preference also in adult flies. How flies process taste information, metabolic status and nutrient value to select appropriate food sources have only now began to be understood. The identification of TH-VUM, Gr43a, cupcake and DA-DL1 neurons is an entry point into the circuits that regulate food decisions. Genetic screens will identify other components of nutrient-sensing circuits and help understand how animals combine external sensory cues with internal metabolic status to make value-based feeding decisions.

Another genetically tractable organism that is amenable for highthroughput genetic screens is the nematode $C$. elegans. In the laboratory, worms are constitutively fed on E. coli feeder lawns. Food is detected by the smell and texture of bacteria $[60,61]$, as well as by sensing indicative factors of microbial metabolism, such as intermediate oxygen concentrations [62]. Caenorhabditis elegans sensory neurons connect to a network of interneurons, which in turn process and convey information to head and body motor neurons. In worms, decision-making behaviours follow evaluation of nutritional status and the presence or quality of food. Worms choose the optimal locomotion strategy, which ranges from sleep-like quiescence and local exploitation to long-distance travel.
When crawling on a bacterial lawn, C. elegans locomotion switches between roaming and dwelling phases [63]. Roaming is fast forward locomotion achieved by undulatory propulsion. On food, roaming periods last on average 1-2 min and they intersperse the longer-lasting dwelling periods (5-10 min) [64]. Dwelling ensures maximal food intake, whereas roaming allows to explore new resources, with the risk of missing the opportunity to fully exploit the local food (Fig 1I). The nutritious value of the food source influences roaming and dwelling; a high nutritious value favours dwelling whereas low food quality favours roaming $[63,65]$. A short 30-min starvation history promotes a strong dwelling response when animals re-enter a bacterial food lawn. This is mediated by serotonergic food-sensing neurons and dopaminergic mechanosensory neurons [61,65]. After prolonged starvation, sudden food encounter triggers sleep-like quiescence, an effect that depends on TGFbeta and insulin signalling [66]. Several genetic studies showed that an interconnected network of molecular pathways and sensory and interneurons regulate the switch between roaming and dwelling (Fig 1J). cGMP and serotonin (5-HT) signalling promotes dwelling $[64,67]$. Conversely, signalling via insulin, TGFbeta and the neuropeptide PDF signalling promote roaming $[64,65]$. Serotonergic, NSM neurons project nerve endings to the food processing pharynx and monitor food intake. They are active during dwelling periods and secrete 5-HT to inhibit roaming [64]. Serotonergic neurons likely act in concert with AWC class and other food chemosensory neurons $[65,67]$. They converge on interneuron circuits and most studies mentioned here identified a cell class termed AIY that receives input from both 5-HT and PDF $[64,65]$. $\mathrm{PDF}$ is a potent arousal factor that can suppress sleep-like behaviour in C. elegans [68]. It is secreted by interneurons as well as by pheromone-sensing ASK and ASI chemosensory neurons [64,68,69]. PDF receptors are expressed by interneurons as well as by sensory neurons, including mechanosensors and oxygen sensors $[64,68,69]$. PDF-dependent roaming and arousal are antagonized by signalling through a neuropeptide $\mathrm{Y}$ receptor (NPYR) homologue, which is encoded by the $n p r-1$ gene [68]. In $n p r-1$ loss-of-function mutants, as well as in wild isolates of $C$. elegans (such as Hawaiian) that bear a polymorphism with a low activity allele of $n p r-1$, roaming depends on sensing high environmental oxygen concentrations [70]. These animals initiate dwelling mostly at the border of bacterial lawns, where bacterial density is highest and oxygen concentrations are low [62]. When the worm population density is high at these sites, npr-1 animals or wild isolates perform a remarkable switch towards social aggregation behaviour. Here, animals actively clump together to form tight feeding aggregates [71]. The action of $n p r-1$, 
oxygen-regulated roaming and social aggregation requires oxygen sensory neurons that regulate the activity of RMG class interneurons, which represent a gap junction hub in the connectome [72,73]. 5-HT- and PDF-secreting neurons and cognate-receptorexpressing neurons do not all form direct chemical synapses with each other. Therefore, the factors described likely act in an endocrine fashion [64]. The individual contributions of each neuron in this distributed regulatory network remain to be elucidated.

Well-fed C. elegans hermaphrodites mostly remain in the local food patch and rarely leave. This strong preference to stay at the local food patch depends on npr-1 signalling. The npr-1 signalling pathway interacts with a tyramine-signalling pathway [74,75]-tyramine, with octopamine, has been discussed as being analogous to the vertebrate adrenergic/noradrenergic system [76]. The history of caloric restriction, as well as the quality of food present at the local patch, can promote leaving behaviour [63].

Upon removal from food, C. elegans enters a locomotor state termed area-restricted search (ARS) that is distinct from either roaming or dwelling behaviours. ARS is characterized by regular forward undulatory crawling, which is frequently interspersed by backward directed motions and reorientation manoeuvres, called reversals and turns, respectively. The net effect of ARS is locomotion trajectories that cover a larger local area [77-79]. The frequency of intermittent reversals versus turns gradually declines with increasing time off food, leading to a switch from ARS to longdistance travel [78]. AWC class food sensory neurons are inactive in the presence of food odours and exhibit prolonged rebound activity upon odour removal [80]. AWC neurons release glutamate and signal to interneuron classes AIB and AIY, whose activity promotes or inhibits reversal and turn frequencies respectively $[77,78,80]$. The prolonged activity dynamics in AWC are negatively counterbalanced by a peptidergic feedback loop: AWC secretes NLP-1 neuropeptides that act on AIA neurons, which in turn secrete an insulin ligand (INS-1) that acts directly on AWC. In the absence of this regulatory loop, ARS is aberrantly enhanced [81].

\section{Neurons that decide who to love or when to fight}

Pheromone perception guides sexual decision-making in mice, flies and worms. Each of these model organisms is able to perceive pheromones through pheromone receptors expressed in peripheral sensory neurons. Pheromones are a discrete class of chemical cues that signal the sex of an individual and promote coordinated motor programmes and physiological changes that are essential for breeding among conspecifics. In mice and flies, these pheromone cues also serve to signal social status and aggressive behaviours.

Mice rely on pheromone detection for sexual mate choice and territorial aggression behaviour. Specifically, TRPC2 is a putative ion channel of the transient receptor potential family, which is expressed in the vomeronasal organ and dictates the choice of sexual partners. Male mice deficient in TRPC2 expression fail to display male-male aggression and decide to initiate sexual and courtship behaviours towards both males and females [82]. Male mice behave differently when encountering a male or a female mouse: male-male interactions usually lead to aggression, whereas male-female interactions trigger courtship behaviour. Choosing one behaviour over the other is regulated not just by peripheral pheromone sensors, but also by CNS neurons. A recent study identified progesterone-receptor-expressing neurons in the ventromedial hypothalamus that are required for sexual behaviour and male aggression. These findings provide insight into how neural circuits in the brain control sexually dimorphic behaviours in vertebrates [83]. In this regard, the fly model pioneered the discovery of a plethora of neurons in the central nervous system that control sexual decisionmaking (Fig 2C). Moreover, flies evolved contact-based pheromone detection through direct activation of taste neurons, a phenomenon that has not yet been found in mice (Fig 2C). In this regard, it has been speculated that mouse major urinary proteins (MUPs) could be contact pheromones, although urine has been mostly used as a stimulus of the vomeronasal organ, which detects volatile pheromones.

Like mice, peer recognition is important for flies to choose appropriate behavioural actions. For example, when encountering another fly, a male receives visual, olfactory and taste sensory cues that he needs to evaluate in order to decide on an appropriate behavioural response (Fig $2 \mathrm{C}$ ). If the signals indicate a potential mate, a male fly will initiate the courtship ritual by chasing the female and singing a species-specific courtship song [84]. In contrast, if the signals indicate a potential rival, the male fly will display stereotypic aggressive behaviours $[85,86]$.

Two transcription factors-fruitless ( $f r u$ ) and doublesex ( $d s x)$ are the main regulators of male fly courtship behaviour, both of which are required for the wiring of the courtship circuitry $[87,88]$. The classic fru mutants court males and females indiscriminately and fail to copulate with females [84]. Through molecular and genetic analysis, the male-specific isoform of Fru protein, FruM, was found to be necessary and sufficient to hardwire the circuitry that produces male courtship behaviour $[89,90]$. FruM is present in

\section{Figure 2. Perceptual decisions: controlling who to love or when to fight.}

(A, B) Mice rely on pheromone detection by neurons in the vomeronasal organ (VNO) for sexual mate choice and aggression behaviour. Male-male interactions usually lead to aggression, whereas male-female interactions trigger courtship behaviour. Male mice deficient in TRP2 expression fail to display male-male aggression and decide to initiate sexual and courtship behaviours towards both males and females. CNS neurons also control these behaviours; choosing one behaviour over the other is controlled by progesterone-receptor-expressing neurons in the ventrolateral aspect of the ventromedial hypothalamus (PR ${ }^{+} \mathrm{VMHvl}$ ). In males, $\mathrm{PR}^{+} \mathrm{VMHVI} \mathrm{neurons}$ mediate courtship and aggression, whereas in females these neurons mediate lordosis. (C) Drosophila male courtship and aggression circuits. Flies rely on pheromone detection in sensory neurons in the antennae and legs to discriminate sexual partners and rivals. Multiple pheromones and correspondent receptors have been identified, as well CNS neurons that regulate courtship and aggression. (D) Hypothetical model of how dimorphic circuits control mate search behaviour in Caenorhabditis elegans males compared to hermaphrodites. Ascarosides (asc) activate sensory neurons common to males and hermaphrodites (purple), as well as male-specific sensory neurons (cyan). RMC interneurons represent a GAP junction hub, and NPR-1 possibly inhibits GAP junction signalling, which balances repulsive and attractive behavioural outputs to downstream motor circuits (not shown). In hermaphrodites, the modulation of sensory neurons by TGFbeta and unknown signals shifts the balance towards repulsion. Note that this model only includes a subset from a diverse ascaroside library, the complexity of which is not yet fully functionally characterized. See Glossary for definitions. 
approximately 2,000 neurons that are distributed among sexually dimorphic sensory, central and motor neuron clusters [91-93]. When all FruM neurons are inhibited, males do not court [92].
Many studies have investigated how the FruM circuit regulates the male decision to court, leading to the identification of distinct classes of FruM neurons that are required for specific steps of male
A

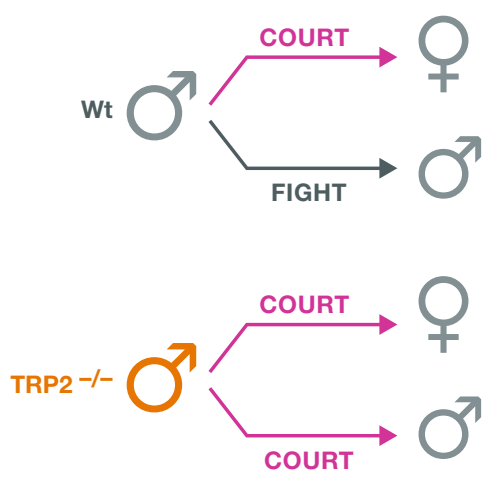

B

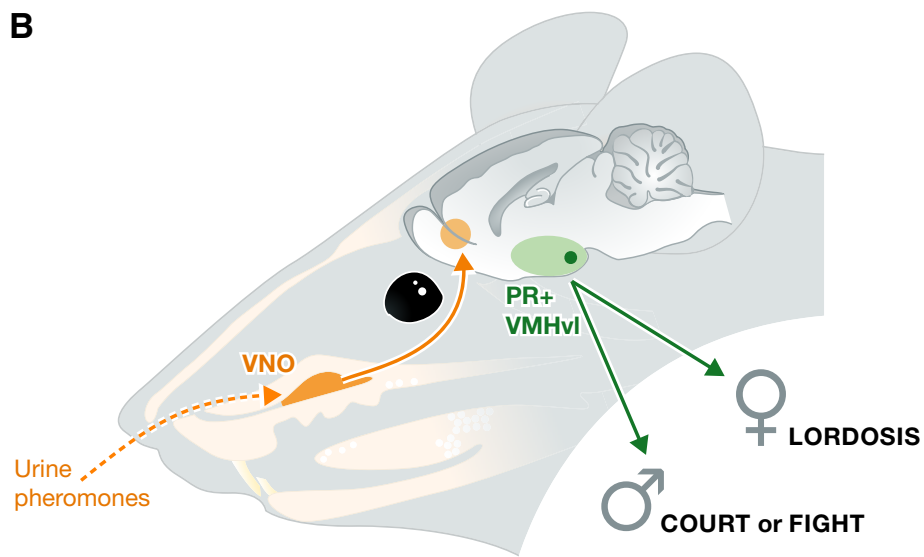

COURT or FIGHT

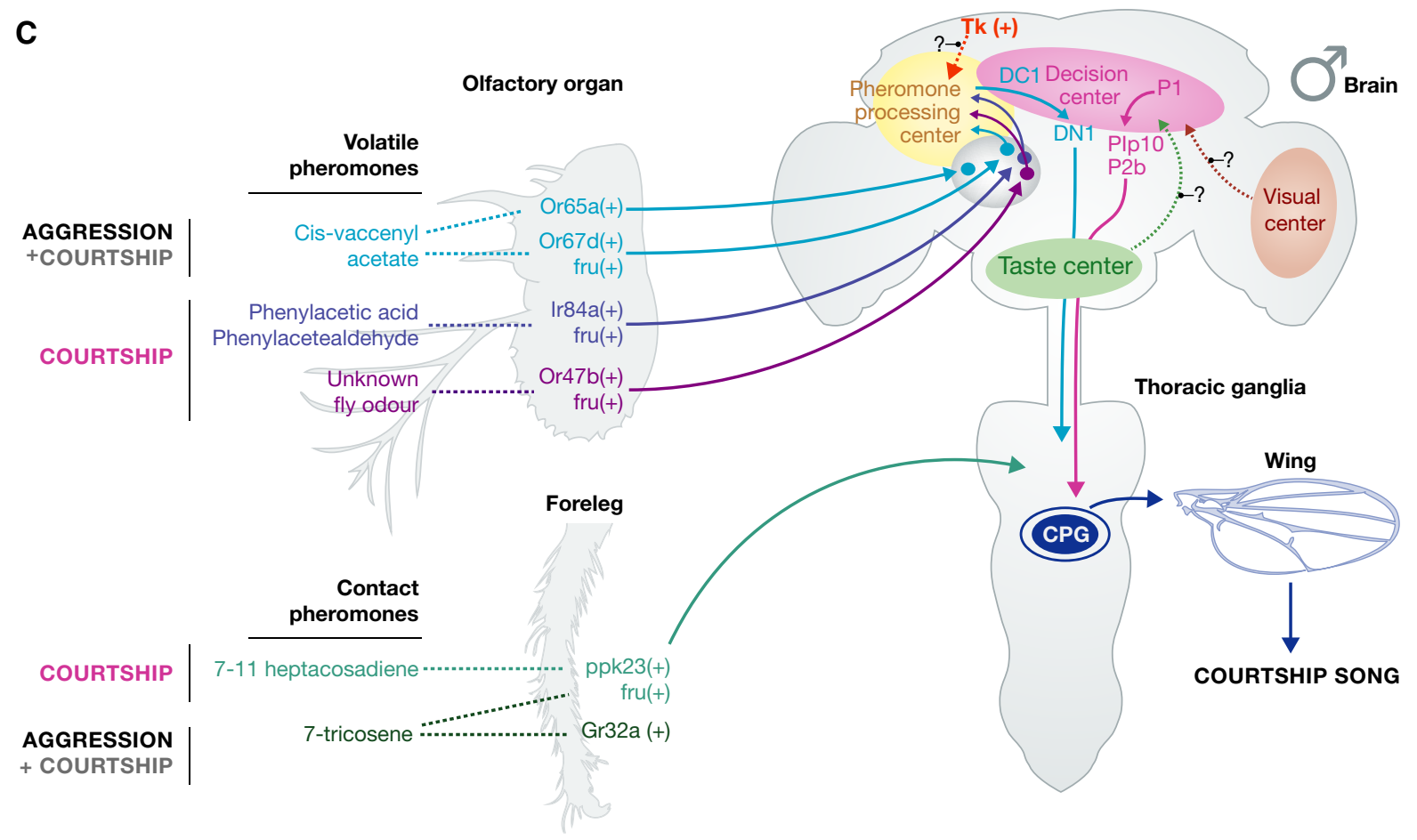

D

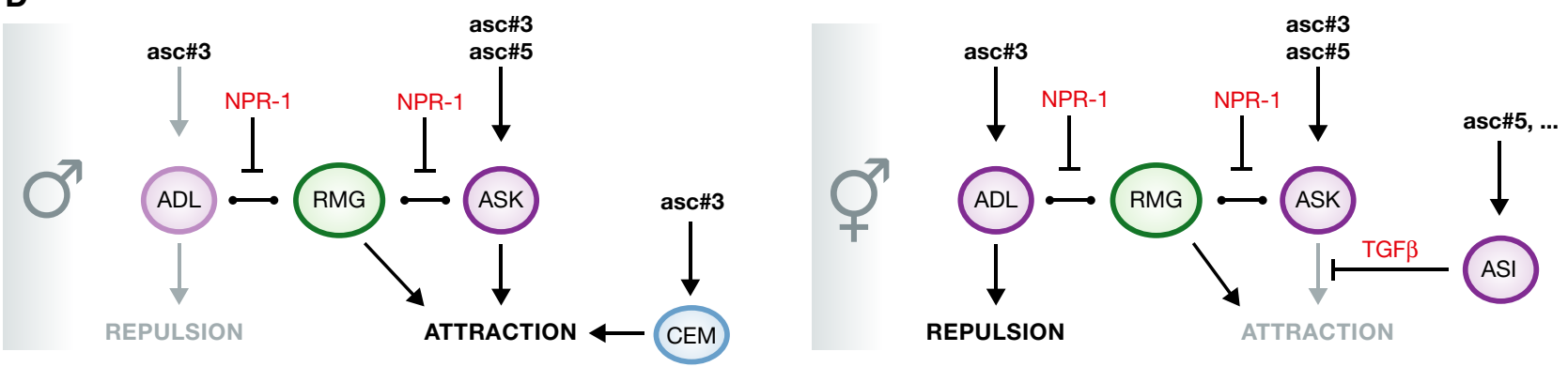


courtship behaviour $[88,94-97]$. Unlike $f r u, d s x$ also regulates sexspecific attributes outside of the nervous system [98].

The interpretation of pheromone signals by the male brain is a key component in the decision to court. FruM labels a subpopulation of olfactory and taste sensory neurons that sense sex-specific pheromones (Fig 2C). One of the best-characterized sex pheromones is cis-vaccenyl acetate (cVA), a male-specific volatile lipid [99]. cVA suppresses male courtship behaviour by activating a class of FruM positive olfactory sensory neurons (OSN) that express Or67d. Or67d neurons project to a sexually dimorphic glomerulus called DA1 in the antennal lobe, which is the primary olfactory relay centre in the fly brain [100]. DA1 projection neurons carry cVA signal to the lateral horn, a higher olfactory processing centre where the signal is processed by the local interneurons $[101,102]$. One of these interneurons, DC1, passes the cVA signal to a descending interneuron, DN1, that carries the information to the thoracic ganglia (TG), where central pattern generators for courtship song are located [95]. From the sensory neurons to the descending interneuron, all components of the cVA circuit express FruM. The behavioural relevance of this circuit has not yet been demonstrated, but it is intriguing to think that DC1 and DN1 interneurons are required for recognition of appropriate mates, preventing males from courting other males.

In addition to $\operatorname{Or} 67 d$, other FruM positive olfactory neurons that express Or47b and IR84a also influence the male decision to court $[103,104]$. While Or47b neurons are activated by an unknown fly odour, Ir84a neurons surprisingly respond to the plant volatiles PAA and PA $[103,105]$. Or47b and Ir84a neurons project to sexually dimorphic Va1v and VL2a glomeruli, respectively. Similar to DA1 PNs, Va1v and VL2a PNs also project to a pheromone-processing region of the lateral horn. These projections are physically segregated from the projection neurons responsive to food-related odours [103]. How DA1 PNs interact with Va1v and VL2a PNs to initiate courtship is under investigation; however, as all known pheromone sensitive PNs project to the lateral horn, this higher order olfactory centre is likely to be part of the decision-making circuit for male courtship initiation.

Beyond volatile pheromones, males also detect potential mates by contact pheromones that are present in fly cuticle. For example, 7-tricosene (7-T) is a male hydrocarbon that is attractive to females and repulsive to males, whereas 7,11-heptacosadiene (7,11-HD) is a female-specific hydrocarbon that acts as an aphrodisiac for males [106]. Recently, 7-T and 7,11-HD were shown to stimulate taste neurons located in male and female forelegs, respectively [96,97]. These paired taste neurons express ppk23 and ppk29. FruM labels a subset of ppk23 foreleg neurons. The function of these genes and activity of FruM positive ppk23 neurons are required for promoting male courtship towards females and preventing courtship towards other males $[96,97,107]$. How ppk23 neurons respond to both 7,11-HD and 7-T, and how these responses regulate opposing courtship behaviours are not understood. Ppk23 neurons may be a heterogeneous population of neurons that carry additional receptors specifically tuned to 7,11-HD or 7-T. Consistent with this hypothesis, feminization of ppk23 neurons increases male-male courtship behaviour, but it does not affect male courtship preference for females [108].

Male flies need to integrate volatile and contact pheromone information to make courtship decisions. In oenocyte-less females, which lack cuticular hydrocarbons, application of 7,11-HD promotes courtship behaviour even in the presence of aversive cVA [109]. This indicates that cVA-sensitive Or67d neurons and 7,11-HD-sensitive ppk23 neurons might converge into the same sensory processing circuit that regulates the onset of male courtship. In an effort to identify such decision-making centres, two independent groups have expressed the heat-sensitive ion channel, $\operatorname{Trp} A 1$, in distinct populations of FruM neurons and screened for male flies that initiated courtship song upon heat-induced neural activation. In both screens, a cluster of approximately 20 male-specific interneurons [87], named P1, were identified (Fig 2C). Activation of the P1 cluster was sufficient to trigger pulse song production and initiate courtship towards females. In contrast, silencing P1 neural activity attenuated natural song and disrupted male courtship [94,110]. P1 neurons are located in the lateral protocerebrum, a brain region that receives inputs from multiple sensory regions, including olfactory and taste systems. Optical imaging experiments showed that P1 neurons responded specifically to female cuticular extracts and this response is inhibited by application of cVA [110]. These experiments suggest that males use P1 neurons to integrate volatile and contact pheromone information in order to discriminate females from males and to initiate courtship towards females. In addition to olfactory and taste sensory cues, there is growing evidence that P1 neurons also receive input from other sensory modalities, including motion-sensitive neurons in the visual system [111]. Altogether, these findings demonstrate that the P1 cluster is a decision-making site in the fly brain that evaluates multiple sensory modalities to direct male initiation of courtship (Sidebar A). The methods that identified P1 also identified potential downstream neuronal clusters pIP10 and P2b, which may be descending command neurons for courtship song production $[94,110]$.

Flies exhibit territorial and aggressive behaviours in the wild and in the laboratory, to compete for resources and establish dominance $[85,86]$. Male flies fight with other males to occupy a food patch or to mate with a female. Female flies fight with other females for food $[97,98]$. Despite this, aggression studies have been long neglected in flies because of the limited occurrence of these aggressive behaviours in this species [112]. However, fly aggression has recently emerged as a new model to study emotional decisions. Similar to mice, the neural circuits and molecules that regulate mating and aggression are heavily intertwined in flies. Sexual determination pathway genes have been shown to play a critical role in establishing aggressive behaviours [113]. For example, Fru regulates the intensity and sex-specific patterns of aggression in both sexes [114,115].

Like courtship behaviour, aggressive behaviours are regulated by volatile and contact pheromones. Many pheromones that are required for appropriate courtship performance are also essential for stereotypic aggressive behaviours. Male-specific anti-aphrodisiac pheromone cVA has been shown to promote aggression through Fru-positive OSN-expressing Or67d [116]. The role of cVA in promoting male-male aggression and inhibiting courtship suggests a direct link between circuits that regulate these two behaviours. In addition to the acute effects of cVA in enhancing aggression, chronic cVA exposure reduces aggressive behaviours that are mediated by social interactions. Like in other animal models, social isolation increases aggressive behaviours in flies. Detection of cVA through another class of OSN that expresses Or65a controls the chronic 
effects of social exposure on aggression [117]. How the diverse effects of cVA are encoded in higher order neurons that receive sensory information from Or67d and Or65a neurons remains unclear (Fig 2C). The effects of cVA on aggression can be modulated by the presence of contact pheromones. Male-specific contact pheromone 7-T is essential for aggression-promoting effects of cVA. It has been shown that 7-T activates bitter-sensing GRNs expressing multiple Grs including Gr32a (Fig 2C). Gr32a mutant males exhibit reduced aggression towards males and become insensitive to the aggression-promoting effects of 7-T, even in the presence of intact cVA signalling. In contrast, Or67d mutants that are anosmic to cVA still show aggressive behaviours in response to 7-T [118]. The hierarchical interaction between the olfactory and taste sensory systems in mediating aggression and courtship is poorly understood. Both sensory systems could converge into a central circuit, the molecular identity of which is yet to be found, that regulates a male's decision to court or fight. A group of sexually dimorphic Fru-positive neurons in the male brain have been recently shown to regulate the intensity of male-male aggression without affecting male-female courtship. These neurons produce a neuropeptide called tachykinin (Tk), which has been also linked to certain forms of aggression in other species, including humans [119]. Male-specific Tk neurons are not command neurons that trigger aggressive behaviours, and they are likely to promote aggression by modulating the internal arousal states of male flies and by influencing the interpretation of chemosensory signals by the central aggression circuits (Fig 2C).

Many sensory and central components of the courtship and aggression circuits have been identified. However, there are still obvious gaps in these circuits to fully understand how flies decide to mate or fight (Sidebar A). The future critical step is to assign functional connectivity among the identified neural clusters and to determine the direction of information flow in the circuit, by measuring neural activity while flies are selecting a behavioural action towards their peers.

In C. elegans, the copulation behaviour of males is triggered by contact and is the most complex motor sequence described in worms thus far. It is mediated in part by a large number of malespecific neurons and muscles, which are superimposed onto a less dimorphic nervous system shared by males and hermaphrodites $[120,121]$. Prior to copulation, reproductive success is facilitated by mate search. In the absence of mating partners, the food-patch leaving behaviour described above is elevated in males in a PDF-dependent manner [69]. Elevated leaving behaviour is suppressed upon hermaphrodite contact, which triggers a prolonged motivational state causing males to remain in the local area [122]. Mate search is facilitated by pheromones termed ascarosides (ASCs), which are modular compounds composed of the sugar ascarylose linked to a carbon side chain and other moieties, for example an indole group. Multiple compounds can be detected in worms, suggesting a complex modular code for pheromone communication [123]. Purified ASCs, when presented to worms alone or as mixtures, can function as attractants as well as repellents in a concentrationdependent manner [124,125]. For example, the indole compound icas\#3 can attract hermaphrodites when presented in the femtomolar range, which also promotes aggregation behaviour [126]. Compared to hermaphrodites, males reduce the amount of the hermaphrodite repellent asc\#3 and increase the production of the potent hermaphrodite attractant ascr\#10 [127]. Ascarosides that regulate mate search are detected by GPCRs expressed in the chemosensory neurons ASI, ADL, ASK and the male-specific CEM neurons (summarized in reference [123]. ADL neurons control avoidance behaviours, whereas ASK and CEM neurons promote attraction. RMG interneurons and npr-1 control the balance between these opposing effects to promote social aggregation [73,125]. Ascaroside-evoked sensory activity in ADL is reduced in males [125], but the basis for this functional polymorphism remains unknown. ASI neurons that secrete TGFbeta have been shown to suppress attraction in hermaphrodites by affecting signalling from ASK and other sensory neurons [128]. In addition, male-specific CEM neurons express asc\#3 receptors and are required for male attraction to asc\#3 $[124,129,130]$; thus, they might override the otherwise repulsive contribution of asc\#3. Taken together, the compound effect of the ASCs that have been tested so far in behavioural assays is repulsive in hermaphrodites and attractive in males. These sex differences in mate search behaviour result from both anatomical and functional sexual dimorphisms in chemosensory circuits (Fig 2D).

\section{Concluding remarks}

Decisions can be difficult and can even go against what one has learned to be the right choice. Obese patients are often faced with difficult decisions about food, when trying to keep a weight-loss diet regimen. Reason would dictate that nutritive food would be deferred over non-nutritive ingredients, such as artificial sweeteners. However, weight loss leads to a drop in key adipose-related hormones, which in turn increase the reward value of food. The notion that decision-making behaviours go beyond the control of reason is grounded on studies in animal models, which we herein review. These studies reveal the molecular and cellular biology underlying decisions for food, sexual partners and rivals. Decisions about food don't solely rely on sensory taste organs but rather also on post-ingestive mechanisms that sense the nutrient value of food. Mice have neurons in the brain that are specialized in sensing increases in serum glucose levels, which trigger dopamine release during sugar ingestion. These neurons are a biological explanation of preference for sugar versus artificial sweeteners (Fig 1C and E). The market share of sugared soda is nearly triple that of diet soda, and the rodent data herein described suggest a biological approach that could potentially be used to regulate sugar consumption. This could be achieved through the development of new artificial sweeteners that act on glucose-sensing neurons, in addition to taste buds.

Nutrient sensing in the brain is not specific to vertebrate models. The fly, D. melanogaster, also contains neurons in the brain that specialize in sensing nutritive compounds (Fig 1G). In addition to glucose-sensitive neurons, a broader spectrum of nutrient-sensitive neurons have been found in flies but not yet in mice. Those include fructose and amino acid sensitive neurons that govern food-related decisions. The fly model is ahead of rodent models, not only with regard to the cellular mechanisms underlying food-related decisions, but also in those underlying decision-making for sexual mates. The advanced understanding of the molecular mechanisms underlying decision-making in the fly is not surprising, given the genetic tractability of this organism: a short life cycle, low 


\section{Sidebar A: In need of answers}

(i) How is taste information integrated with nutrient value?

(ii) Do metabolic hormones control glucose-sensing neuronal circuits to modulate the reward value of sugar?

(iii) Which nutrient-sensing neuronal circuits control the reward value of fat?

(iv) How does the metabolic status change the valence of nutrients?

(v) How do P1 neurons in the male fly brain integrate multiple sensory inputs?

(vi) How do the aggression and mating circuits interact in the fly brain?

(vii) What is the neural activity correlate of arousal in C. elegans, and how does it control decisions of choosing among various foraging strategies?

(viii) What is the logical syntax and function of the complex modular pheromone communication system in C. elegans?

\section{Acknowledgements}

We thank Eleanor Clowney, Emily Dennis, Danielle Sonnenberg and Harris Kaplan for critically reading the manuscript, The Rockefeller University (NY), Klarman Family Foundation Grants Program in Eating Disorders Research (NY), the IMP (MZ) and Boehringer Ingelheim (MZ) for funding. NY was supported by a Human Frontier Science Program Long-Term Postdoctoral Fellowship. We also thank Gulbenkian Science Institute and FCT-Portugal for support given to AID. Gulbenkian Foundation and Fundação para a Ciência e Tecnologia (Portugal AID)

\section{Author contributions}

NY, MZ and AID composed the figures and together wrote the paper.

\section{Conflict of interest}

The authors declare that they have no conflict of interest.

\section{References}

maintenance costs, coupled to massive and rapid generation of reagents that probe neuronal and molecular function. In this regard, another model able to compete with flies is the worm C. elegans, which has a life cycle of 3 days, a completely mapped neural connectome, and decision-making behaviours that encompass acute navigational taxis decisions and choices among various longer-term locomotion strategies. Caenorhabditis elegans decides between the full exploitation of a food source-during which it can form social feeding aggregates with conspecifics - with explorative elements expressed by local roaming, or food-patch leaving. Exploration either enables the localization of new, possibly more nutritious food sources, or ensures a balance with other drives, such as mate search (Fig 1I). Most signalling pathways described here (insulin, TGFbeta, cGMP, PDF and npr-1) have also been described in the regulation of sleep-like quiescence states in C. elegans. Therefore, these behavioural strategies can be conceptualized by postulating an arousal axis ranging from sleep-like quiescence to high arousal levels during active search. In this model, arousal is associated with increased risk taking (Fig 1J) (Sidebar A). In all these cases, the choice of locomotion strategy is influenced by food availability/quality and nutritional status, and mediated by conserved neuroendocrine pathways. Interestingly, similar decision strategies are implicated in social behaviours like aggregation and mate search, which are additionally controlled by a surprisingly complex repertoire of pheromone cues that balance attraction and repulsion between animals (Sidebar A). Male-specific behaviours rely on both sexually dimorphic nervous systems and the reprogramming of neurons common to both sexes (Fig 2D).

In addition to biological mechanisms that are perhaps influenced by internal states (such as food, water or sleep deprivation), decisionmaking behaviours are considerably linked to learning $[55,56]$. However, this aspect is out of the scope of this review and has been comprehensively reviewed elsewhere [131-133].

The tools of molecular genetics have identified molecular and cellular mechanisms underlying decision-making behaviours in animal models. Whether these molecular mechanisms, particularly those demonstrated in mice, are homologous in humans remains to be determined. However, these studies underscore that, just as in animals, biology can trap people into certain decisions.
1. Ho TH, Lim N, Camerer CF (2006) Modeling the psychology of consumer and firm behavior with behavioral economics. J Mark Res 43 $307-331$

2. Camerer C (1999) Behavioral economics: reunifying psychology and economics. Proc Natl Acad Sci USA 96: 10575-10577

3. Ariely D (2008) Predictably Irrational: the Hidden Forces That Shape Our Decisions. New York, NY: HarperCollins Books

4. Kahneman D, Fredrickson BL, Redelmeier D, Schreiber CA (1993) When more pain is preferred to less: adding a better end. Psychol Sci 4: $401-405$

5. Ariely D, Loewenstein G (2000) When does duration matter in judgment and decision making? J Exp Psychol Gen 129: 508-523

6. Ariely D (1998) Combining experiences over time: the effects of duration, intensity changes and on-line measurements on retrospective pain evaluations. J Behau Decis Making 11: 19-45

7. Glimcher PW, Rustichini A (2004) Neuroeconomics: the consilience of brain and decision. Science 306: 447-452

8. Ariely D, Berns GS (2010) Neuromarketing: the hope and hype of neuroimaging in business. Nat Reu Neurosci 11: 284-292

9. Padoa-Schioppa C, Assad JA (2008) The representation of economic value in the orbitofrontal cortex is invariant for changes of menu. Nat Neurosci 11: 95-102

10. Rushworth Matthew FS, Noonan MaryAnn P, Boorman Erie D, Walton Mark E, Behrens Timothy E (2011) Frontal cortex and reward-guided learning and decision-making. Neuron 70: $1054-1069$

11. Montague PR, Berns GS (2002) Neural economics and the biological substrates of valuation. Neuron 36: $265-284$

12. Rangel A (2013) Regulation of dietary choice by the decision-making circuitry. Nat Neurosci 16: 1717-1724

13. Jacobson MF (2005) Liquid Candy. Center for Science in the Public Interest. 1-46

14. Sicher J (2011) Soft drink market shares. Beverage Digest 59: 1-2

15. Domingos Al, Vaynshteyn J, Voss HU, Ren X, Gradinaru V, Zang F, Deisseroth K, de Araujo IE, Friedman J (2011) Leptin regulates the reward value of nutrient. Nat Neurosci 14: 1562-1568

16. de Araujo IE, Oliveira-Maia AJ, Sotnikova TD, Gainetdinov RR, Caron MG, Nicolelis MAL, Simon SA (2008) Food reward in the absence of taste receptor signaling. Neuron 57: $930-941$ 
17. de Araujo IE, Lin T, Veldhuizen MG, Small DM (2013) Metabolic regulation of brain response to food cues. Curr Biol 23: 878-883

18. Domingos Al, Sordillo A, Dietrich MO, Liu Z-W, Tellez LA, Vaynshteyn J, Ferreira JG, Ekstrand MI, Horvath TL, de Araujo IE (2013) Hypothalamic melanin concentrating hormone neurons communicate the nutrient value of sugar. Elife 2: e01462

19. Burdakov D, Gerasimenko O, Verkhratsky A (2005) Physiological changes in glucose differentially modulate the excitability of hypothalamic melanin-concentrating hormone and orexin neurons in situ. J Neurosci 25: $2429-2433$

20. Kong D, Vong L, Parton LE, Ye C, Tong Q, Hu X, Choi B, Brüning JC, Lowell BB (2010) Glucose stimulation of hypothalamic MCH neurons involves K(ATP) channels, is modulated by UCP2, and regulates peripheral glucose homeostasis. Cell Metab 12: 545-552

21. Buch T, Heppner FL, Tertilt C, Heinen TJAJ, Kremer M, Wunderlich FT, Jung S, Waisman A (2005) A Cre-inducible diphtheria toxin receptor mediates cell lineage ablation after toxin administration. Nat Methods 2: $419-426$

22. Jego S, Glasgow SD, Herrera CG, Ekstrand M, Reed SJ, Boyce R, Friedman J, Burdakov D, Adamantidis AR (2013) Optogenetic identification of a rapid eye movement sleep modulatory circuit in the hypothalamus. Nat Neurosci 16: 1637-1643

23. Pérez CA, Stanley SA, Wysocki RW, Havranova J, Ahrens-Nicklas R, Onyimba F, Friedman JM (2011) Molecular annotation of integrative feeding neural circuits. Cell Metab 13: 222-232

24. Liu Z, Zhou J, Li Y, Hu F, Lu Y, Ma M, Feng Q, Zhang J, Wang D, Zeng J (2014) Dorsal raphe neurons signal reward through 5-HT and glutamate. Neuron 81: 1360-1374

25. Sclafani A, Mann S (1987) Carbohydrate taste preferences in rats: glucose, sucrose, maltose, fructose and polycose compared. Physiol Behav 40: $563-568$

26. Nelson G, Hoon MA, Chandrashekar J, Zhang Y, Ryba NJ, Zuker CS (2001) Mammalian sweet taste receptors. Cell 106: 381-390

27. Leinninger $\mathrm{CM}$, Opland DM, Jo Y-H, Faouzi M, Christensen L, Cappellucci LA, Rhodes CJ, Gnegy ME, Becker JB, Pothos EN (2011) Leptin action via neurotensin neurons controls orexin, the mesolimbic dopamine system and energy balance. Cell Metab 14: 313-323

28. Thompson JL, Borgland SL (2013) Presynaptic leptin action suppresses excitatory synaptic transmission onto ventral tegmental area dopamine neurons. Biol Psychiatry 00: 1-9

29. Yarmolinsky DA, Zuker CS, Ryba NJ (2009) Common sense about taste: from mammals to insects. Cell 139: 234-244

30. Nayak SV, Singh RN (1983) Sensilla on the tarsal segments and mouthparts of adult Drosophila melanogaster meigen (Diptera: Drosophilidae). Int J Insect Morphol Embryol 12: 273-291

31. Stocker RF (1994) The organization of the chemosensory system in Drosophila melanogaster: a review. Cell Tissue Res 275: 3-26

32. Scott K, Brady R, Cravchik A, Morozov P, Rzhetsky A, Zuker C, Axel R (2001) A chemosensory gene family encoding candidate gustatory and olfactory receptors in Drosophila. Cell 104: 661-673

33. Dunipace L, Meister S, McNealy C, Amrein H (2001) Spatially restricted expression of candidate taste receptors in the Drosophila gustatory system. Curr Biol 11: 822-835

34. Clyne PJ, Warr CG, Carlson JR (2000) Candidate taste receptors in Drosophila. Science 287: 1830-1834

35. Pollack GS, Balakrishnan R (1997) Taste sensilla of flies: function, central neuronal projections, and development. Microsc Res Tech 39 $532-546$
36. Chyb S, Dahanukar A, Wickens A, Carlson JR (2003) Drosophila Gr5a encodes a taste receptor tuned to trehalose. Proc Natl Acad Sci USA 100(Suppl 2): 14526-14530

37. Moon SJ, Köttgen M, Jiao Y, Xu H, Montell C (2006) A taste receptor required for the caffeine response in vivo. Curr Biol 16: 1812-1817

38. Jiao Y, Moon SJ, Wang X, Ren Q, Montell C (2008) Gr64f is required in combination with other gustatory receptors for sugar detection in Drosophila. Curr Biol 18: 1797-1801

39. Dahanukar A, Lei Y-T, Kwon JY, Carlson JR (2007) Two Gr genes underlie sugar reception in Drosophila. Neuron 56: 503-516

40. Benton R, Vannice KS, Gomez-Diaz C, Vosshall LB (2009) Variant ionotropic glutamate receptors as chemosensory receptors in Drosophila. Cell 136: $149-162$

41. Rytz R, Croset V, Benton R (2013) Ionotropic receptors (IRs): chemosensory ionotropic glutamate receptors in Drosophila and beyond. Insect Biochem Mol Biol 43: 888-897

42. Kellenberger S, Schild L (2002) Epithelial sodium channel/degenerin family of ion channels: a variety of functions for a shared structure. Physiol Reu 82: 735-767

43. Cameron P, Hiroi M, Ngai J, Scott K (2010) The molecular basis for water taste in Drosophila. Nature 465: 91-95

44. Masek P, Keene AC (2013) Drosophila fatty acid taste signals through the PLC pathway in sugar-sensing neurons. PLoS Genet 9: e1003710

45. Toshima N, Tanimura T (2012) Taste preference for amino acids is dependent on internal nutritional state in Drosophila melanogaster. J Exp Biol 215: 2827-2832

46. Dethier VG (1976) The Hungry Fly. Cambridge, MA: Harvard University Press

47. Inagaki HK, Ben-Tabou de-Leon S, Wong AM, Jagadish S, Ishimoto $\mathrm{H}$, Barnea G, Kitamoto T, Axel R, Anderson DJ (2012) Visualizing neuromodulation in vivo: TANGO-mapping of dopamine signaling reveals appetite control of sugar sensing. Cell 148: $583-595$

48. Marella S, Mann K, Scott K (2012) Dopaminergic modulation of sucrose acceptance behavior in Drosophila. Neuron 73: 941-950

49. Dus M, Min S, Keene AC, Lee GY, Suh CSB (2011) Taste-independent detection of the caloric content of sugar in Drosophila. Proc Natl Acad Sci USA 108: $11644-11649$

50. Stafford JW, Lynd KM, Jung AY, Gordon MD (2012) Integration of taste and calorie sensing in Drosophila. J Neurosci 32: 14767-14774

51. Dus M, Ai M, Suh GSB (2013) Taste-independent nutrient selection is mediated by a brain-specific $\mathrm{Na}(+) /$ solute co-transporter in Drosophila. Nat Neurosci 16: $526-528$

52. Miyamoto T, Slone J, Song X, Amrein H (2012) A fructose receptor functions as a nutrient sensor in the Drosophila brain. Cell 151: 1113-1125

53. Burke CJ, Waddell S (2011) Remembering nutrient quality of sugar in Drosophila. Curr Biol 21: 746-750

54. Fujita M, Tanimura T (2011) Drosophila evaluates and learns the nutritional value of sugars. Curr Biol 21: 751-755

55. Liu C, Plaçais P-Y, Yamagata N, Pfeiffer BD, Aso Y, Friedrich AB, Siwanowicz I, Rubin GM, Preat T, Tanimoto H (2013) A subset of dopamine neurons signals reward for odour memory in Drosophila. Nature 488: $512-516$

56. Burke CJ, Huetteroth W, Owald D, Perisse E, Krashes MJ, Das G, Gohl D, Silies M, Certel S, Waddell S (2012) Layered reward signalling through octopamine and dopamine in Drosophila. Nature 492: 433-437

57. Ribeiro C, Dickson BJ (2010) Sex peptide receptor and neuronal TOR/ S6K signaling modulate nutrient balancing in Drosophila. Curr Biol 20 $1000-1005$ 
58. Vargas MA, Luo N, Yamaguchi A, Kapahi P (2010) A role for S6 kinase and serotonin in postmating dietary switch and balance of nutrients in D. melanogaster. Curr Biol 20: 1006-1011

59. Bjordal M, Arquier N, Kniazeff J, Pin JP, Leopold P (2014) Sensing of amino acids in a dopaminergic circuitry promotes rejection of an incomplete diet in Drosophila. Cell 156: 510-521

60. Bargmann $\mathrm{Cl}$ (2006) Chemosensation in C. elegans. WormBook: the online review of $C$. elegans biology. 1-29

61. Sawin ER, Ranganathan R, Horvitz HR (2000) Caenorhabditis elegans locomotory rate is modulated by the environment through a dopaminergic pathway and by experience through a serotonergic pathway. Neuron 26: 619-631

62. Gray JM, Karow DS, Lu H, Chang AJ, Chang JS, Ellis RE, Marletta MA, Bargmann $\mathrm{Cl}$ (2004) Oxygen sensation and social feeding mediated by a C. elegans guanylate cyclase homologue. Nature 430: 317-322

63. Shtonda BB (2006) Dietary choice behavior in Caenorhabditis elegans. J Exp Biol 209: 89-102

64. Flavell SW, Pokala N, Macosko EZ, Albrecht DR, Larsch J, Bargmann Cl (2013) Serotonin and the neuropeptide PDF initiate and extend opposing behavioral states in Caenorhabditis elegans. Cell 154: 1023-1035

65. Ben Arous J, Laffont S, Chatenay D (2009) Molecular and sensory basis of a food related two-state behavior in C. elegans. PLOS ONE 4: e7584

66. You Y-J, Kim J, Raizen DM, Avery L (2008) Insulin, cGMP, and TGF-beta signals regulate food intake and quiescence in C. elegans: a model for satiety. Cell Metab 7: 249-257

67. Fujiwara M, Sengupta P, McIntire SL (2002) Regulation of body size and behavioral state of $C$. elegans by sensory perception and the EGL-4 cGMP-dependent protein kinase. Neuron 36: 1091-1102

68. Choi S, Chatzigeorgiou M, Taylor KP, Schafer WR, Kaplan JM (2013) Analysis of NPR-1 reveals a circuit mechanism for behavioral quiescence in Caenorhabditis elegans. Neuron 78: 869-880

69. Barrios A, Ghosh R, Fang C, Emmons SW, Barr MM (2012) PDF-1 neuropeptide signaling modulates a neural circuit for mate-searching behavior in C. elegans. Nat Neurosci 15: 1675-7682

70. Cheung BHH, Cohen M, Rogers C, Albayram O, de Bono M (2005) Experience-dependent modulation of $C$. elegans behavior by ambient oxygen. Curr Biol 15: $905-917$

71. de Bono M, Bargmann Cl (1998) Natural variation in a neuropeptide $Y$ receptor homolog modifies social behavior and food response in C. elegans. Cell 94: 679-689

72. Busch KE, Laurent P, Soltesz Z, Murphy RJ, Faivre O, Hedwig B, Thomas M, Smith HL, de Bono M (2012) Tonic signaling from 02 sensors sets neural circuit activity and behavioral state. Nat Neurosci 15: 581-591

73. Macosko EZ, Pokala N, Feinberg EH, Chalasani SH, Butcher RA, Clardy J, Bargmann Cl (2009) A hub-and-spoke circuit drives pheromone attraction and social behaviour in C. elegans. Nature 458: 1171-1175

74. Bendesky A, Tsunozaki M, Rockman MV, Kruglyak L, Bargmann Cl (2011) Catecholamine receptor polymorphisms affect decision-making in C. elegans. Nature 472: 313-318

75. Gloria-Soria A, Azevedo RBR (2008) npr-1 regulates foraging and dispersal strategies in Caenorhabditis elegans. Curr Biol 18: 1694-1699

76. Roeder T (1999) Octopamine in invertebrates. Prog Neurobiol 59: 533-561

77. Tsalik EL, Hobert O (2003) Functional mapping of neurons that control locomotory behavior in Caenorhabditis elegans. J Neurobiol 56: 178-197

78. Gray JM, Hill JJ, Bargmann Cl (2005) A circuit for navigation in Caenorhabditis elegans. Proc Natl Acad Sci USA 102: 3184-3191
79. Hills T, Brockie PJ, Maricq AV (2004) Dopamine and glutamate control area-restricted search behavior in Caenorhabditis elegans. J Neurosci 24 1217-1225

80. Chalasani SH, Chronis N, Tsunozaki M, Gray JM, Ramot D, Goodman MB, Bargmann Cl (2007) Dissecting a circuit for olfactory behaviour in Caenorhabditis elegans. Nature 450: 63-70

81. Chalasani SH, Kato S, Albrecht DR, Nakagawa T, Abbott LF, Bargmann $\mathrm{Cl}$ (2010) Neuropeptide feedback modifies odor-evoked dynamics in Caenorhabditis elegans olfactory neurons. Nat Neurosci 13: 615-621

82. Stowers L, Holy TE, Meister M, Dulac C, Koentges G (2002) Loss of sex discrimination and male-male aggression in mice deficient for TRP2. Science 295: 1493-1500

83. Yang CF, Chiang MC, Gray DC, Prabhakaran M, Alvarado M, Juntti SA, Unger EK, Wells JA, Shah NM (2013) Sexually dimorphic neurons in the ventromedial hypothalamus govern mating in both sexes and aggression in males. Cell 153: 896-909

84. Hall JC (1994) The mating of a fly. Science 264: 1702-1714

85. Dow MA, von Schilcher $F$ (1975) Aggression and mating success in Drosophila melanogaster. Nature 254: 511-512

86. Lee G, Hall JC (2000) A newly uncovered phenotype associated with the fruitless gene of Drosophila melanogaster: aggression-like head interactions between mutant males. Behau Genet 30: $263-275$

87. Kimura K-I, Hachiya T, Koganezawa M, Tazawa T, Yamamoto D (2008) Fruitless and doublesex coordinate to generate male-specific neurons that can initiate courtship. Neuron 59: 759-769

88. Kimura K-I, Ote M, Tazawa T, Yamamoto D (2005) Fruitless specifies sexually dimorphic neural circuitry in the Drosophila brain. Nature 438: $229-233$

89. Demir E, Dickson BJ (2005) fruitless splicing specifies male courtship behavior in Drosophila. Cell 121: $785-794$

90. Manoli DS, Foss M, Villella A, Taylor BJ, Hall JC, Baker BS (2005) Male-specific fruitless specifies the neural substrates of Drosophila courtship behaviour. Nature 436: $395-400$

91. Cachero S, Ostrovsky AD, Yu JY, Dickson BJ, Jefferis GSXE (2010) Sexual dimorphism in the fly brain. Curr Biol 20: 1589-1601

92. Stockinger P, Kvitsiani D, Rotkopf S, Tirian L, Dickson BJ (2005) Neural circuitry that governs Drosophila male courtship behavior. Cell 121: 795-807

93. Yu JY, Kanai MI, Demir E, Jefferis GSXE, Dickson BJ (2010) Cellular organization of the neural circuit that drives Drosophila courtship behavior. Curr Biol 20: 1602-1614

94. von Philipsborn AC, Liu T, Yu JY, Masser C, Bidaye SS, Dickson BJ (2011) Neuronal control of Drosophila courtship song. Neuron 69: 509-522

95. Ruta V, Datta SR, Vasconcelos ML, Freeland J, Looger LL, Axel R (2010) A dimorphic pheromone circuit in Drosophila from sensory input to descending output. Nature 468: 686-690

96. Thistle R, Cameron P, Ghorayshi A, Dennison L, Scott K (2012) Contact chemoreceptors mediate male-male repulsion and male-female attraction during Drosophila courtship. Cell 149: 1140-1151

97. Toda H, Zhao X, Dickson BJ (2012) The Drosophila female aphrodisiac pheromone activates ppk23(+) sensory neurons to elicit male courtship behavior. Cell Rep 1: 599-607

98. Rideout EJ, Dornan AJ, Neville MC, Eadie S, Goodwin SF (2010) Control of sexual differentiation and behavior by the doublesex gene in Drosophila melanogaster. Nat Neurosci 13: $458-466$

99. Brieger G, Butterworth FM (1970) Drosophila melanogaster: identity of male lipid in reproductive system. Science 167: 1262 
100. Kurtovic A, Widmer A, Dickson BJ (2007) A single class of olfactory neurons mediates behavioural responses to a Drosophila sex pheromone. Nature 446: 542-546

101. Datta SR, Vasconcelos ML, Ruta V, Luo S, Wong A, Demir E, Flores J, Balonze K, Dickson BJ, Axel R (2008) The Drosophila pheromone cVA activates a sexually dimorphic neural circuit. Nature 452: 473-477

102. Kohl J, Ostrovsky AD, Frechter S, Jefferis GSXE (2013) A bidirectional circuit switch reroutes pheromone signals in male and female brains. Cell 155: 1610-1623

103. Grosjean Y, Rytz R, Farine J-P, Abuin L, Cortot J, Jefferis GS, Benton R (2011) An olfactory receptor for food-derived odours promotes male courtship in Drosophila. Nature 478: 236-240

104. Root CM, Masuyama K, Green DS, Enell LE, Nassel DR, Lee C-H, Wang JW (2008) A presynaptic gain control mechanism fine-tunes olfactory behavior. Neuron 59: 311-321

105. van der Goes van Naters W, Carlson JR (2007) Receptors and neurons for fly odors in Drosophila. Curr Biol 17: 606-612

106. Ferveur J-F (2005) Cuticular hydrocarbons: their evolution and roles in Drosophila Pheromonal communication. Behau Genet 35: 279-295

107. Lu B, LaMora A, Sun Y, Welsh MJ, Ben-Shahar Y (2012) ppk23-Dependent chemosensory functions contribute to courtship behavior in Drosophila melanogaster. PLoS Genet 8: e1002587

108. Lu B, Zelle KM, Seltzer R, Hefetz A, Ben-Shahar Y (2014) Feminization of pheromone-sensing neurons affects mating decisions in Drosophila males. Biol Open 3: $152-160$

109. Billeter J-C, Atallah J, Krupp JJ, Millar JG, Levine JD (2009) Specialized cells tag sexual and species identity in Drosophila melanogaster. Nature 461: 987-991

110. Kohatsu S, Koganezawa M, Yamamoto D (2011) Female contact activates male-specific interneurons that trigger stereotypic courtship behavior in Drosophila. Neuron 69: 498-508

111. Pan Y, Meissner GW, Baker BS (2012) Joint control of Drosophila male courtship behavior by motion cues and activation of male-specific P1 neurons. Proc Natl Acad Sci USA 109: 10065-10070

112. Zwarts L, Versteven M, Callaerts P (2012) Genetics and neurobiology of aggression in Drosophila. Fly 6: $35-48$

113. Baier A, Wittek B, Brembs B (2002) Drosophila as a new model organism for the neurobiology of aggression? J Exp Biol 205: 1233-1240

114. Nilsen SP, Chan Y-B, Huber R, Kravitz EA (2004) Gender-selective patterns of aggressive behavior in Drosophila melanogaster. Proc Natl Acad Sci USA 101: 12342-12347

115. Vrontou E, Nilsen SP, Demir E, Kravitz EA, Dickson BJ (2006) fruitless regulates aggression and dominance in Drosophila. Nat Neurosci 9: $1469-1471$

116. Wang L, Anderson DJ (2010) Identification of an aggression-promoting pheromone and its receptor neurons in Drosophila. Nature 463: $227-231$

117. Liu W, Liang X, Gong J, Yang Z, Zhang Y-H, Zhang J-X, Rao Y (2011) Social regulation of aggression by pheromonal activation of Or65a olfactory neurons in Drosophila. Nat Neurosci 14: 896-902
118. Wang L, Han X, Mehren J, Hiroi M, Billeter J-C, Miyamoto T, Amrein $H$, Levine JD, Anderson DJ (2011) Hierarchical chemosensory regulation of male-male social interactions in Drosophila. Nat Neurosci 14: $757-762$

119. Asahina K, Watanabe K, Duistermars B], Hoopfer E, González CR, Eyjólfssótttir EA, Perona P, Anderson DJ (2014) Tachykinin-expressing neurons control male-specific aggressive arousal in Drosophila. Cell 156 $221-235$

120. Barr M (2006) Male mating behavior. WormBook: the online review of C. elegans biology.

121. Jarrell TA, Wang Y, Bloniarz AE, Brittin CA, Xu M, Thomson JN, Albertson DG, Hall DH, Emmons SW (2012) The connectome of a decision-making neural network. Science 337: 437-444

122. Barrios A, Nurrish S, Emmons SW (2008) Sensory regulation of C. elegans male mate-searching behavior. Curr Biol 18: 1865-1871

123. Ludewig AH, Schroeder FC (2013) Ascaroside signaling in C. elegans. WormBook: the online review of $C$. elegans biology. 1-22

124. Srinivasan J, Kaplan F, Ajredini R, Zachariah C, Alborn HT, Teal PE, Malik RU, Edison AS, Sternberg PW, Schroeder FC (2008) A blend of small molecules regulates both mating and development in Caenorhabditis elegans. Nature 454: 1115-1118

125. Jang H, Kim K, Neal SJ, Macosko E, Kim D, Butcher RA, Zeiger DM, Bargmann Cl, Sengupta P (2012) Neuromodulatory state and sex specify alternative behaviors through antagonistic synaptic pathways in C. elegans. Neuron 75: 585-592

126. Srinivasan J, von Reuss SH, Bose N, Zaslaver A, Mahanti P, Ho MC, O'Doherty OG, Edison AS, Sternberg PW, Schroeder FC (2012) A modular library of small molecule signals regulates social behaviors in Caenorhabditis elegans. PLoS Biol 10: e1001237

127. Izrayelit Y, Srinivasan J, Campbell SL, Jo Y, von Reuss SH, Genoff MC, Sternberg PW, Schroeder FC (2012) Targeted metabolomics reveals a male pheromone and sex-specific ascaroside biosynthesis in Caenorhabditis elegans. ACS Chem Biol 7: 1321-1325

128. White JQ, Jorgensen EM (2012) Sensation in a single neuron pair represses male behavior in hermaphrodites. Neuron 75 : $593-600$

129. Park D, O'Doherty I, Somvanshi RK, Bethke A, Schroeder FC, Kumar $U$, Riddle DL (2012) Interaction of structure-specific and promiscuous G-protein-coupled receptors mediates small-molecule signaling in Caenorhabditis elegans. Proc Natl Acad Sci USA 109 9917-9922

130. White JQ, Nicholas TJ, Gritton J, Truong L, Davidson ER, Jorgensen EM (2007) The sensory circuitry for sexual attraction in C. elegans males. Curr Biol 17: 1847-1857

131. Brembs B (2011) Spontaneous decisions and operant conditioning in fruit flies. Behau Process 87: 157-164

132. Dayan P, Daw ND (2008) Decision theory, reinforcement learning, and the brain. Cogn Affect Behau Neurosci 8: 429-453

133. Sasakura H, Mori I (2013) Behavioral plasticity, learning, and memory in C. elegans. Curr Opin Neurobiol 23: 92-99 